\title{
Heterogeneity of Pharmacy Education in Europe ${ }^{\dagger}$
}

\section{Jeffrey Atkinson}

Pharmacolor Consultants Nancy, 12 rue de Versigny, Villers 54600, France;

E-Mail: jeffrey.atkinson@univ-lorraine.fr; Tel./Fax: +33-383-27-37-03

$\dagger$ This article is dedicated to the memory of Bart Rombaut, co-ordinator of the PHARMINE project, who passed away in January 2014.

Received: 12 June 2014; in revised form: 3 August 2014 / Accepted: 11 August 2014 /

Published: 15 August 2014

\begin{abstract}
The 1985 European Economic Community (EEC) directive on the sectoral profession of pharmacy assumed that the comparability of pharmacy education across Europe could provide a basis for the mutual recognition of diplomas. A study by the European Association of Faculties of Pharmacy (EAFP) in 1994 showed, however, that there was large variability in course content. The 2011 PHARMINE study investigated whether such variability had decreased. Information from across the EU countries on the number of contact hours in specific subject areas was compared for the years of 1994 and 2011. Data was obtained from the original 1994 Bourlioux/EAFP study and the 2011 PHARMINE survey. As the latter was based on the 1994 survey, the questions and categories were similar. Results show that there has not been a fall in the variability of course content. Furthermore, EU pharmacy courses have become more "clinical" with an increase in contact hours in the subject area of medicinal sciences.
\end{abstract}

Keywords: pharmacy; education; clinical; policy; EU

\section{Introduction}

Pharmacy education and practice in the EU are under the auspices of the directive on sectoral professions that aims at bringing education in line with practice, and ensuring that education throughout the EU is harmonized leading to mutual recognition of diplomas by member states.

The 1985 European Economic Community directive [1] pertained to "the coordination of provisions laid down by law, regulation or administrative action in respect of certain activities in the field of 
pharmacy" and this "... with a view to achieving mutual recognition of diplomas". The 1985 directive set out the organizational aspects of pharmacy studies (overall duration, duration of traineeship) and the subject areas of a European pharmacy degree course (see annex), this with a view to fulfilment of the specific activities of a pharmacist in the EU, the latter also set out in the directive.

The 1985 directive stated that "the broad comparability of training courses in the Member States enables coordination in this field to be confined to the requirement that minimum standards be observed, thus leaving the Member States freedom of organization as regards teaching". Thus based on the assumption that courses in Europe were broadly comparable-with little variation in the subject matters treated-recognition of qualifications for sectoral profession of pharmacy could be automatic.

In the early 1990s, the European Association of Faculties of Pharmacy (EAFP) [2] questioned this assumption. P. Bourlioux and others from the EAFP surveyed pharmacy courses in the 11 European Economic Community member states (Belgium, Denmark, France, Germany, Greece, Ireland, Italy, The Netherlands, Portugal, Spain, and the United Kingdom) with pharmacy faculties [3]. They found that although globally the emphasis was on chemical sciences (CHEMSCI), there was wide variation in contact hours in other subjects, for example, medicinal sciences (MEDISCI).

In 2011, the PHARMINE (PHARMacy Education IN Europe) EU-funded project [4] in preparation of the 2013 revision of the European directive [5], revisited this problem to see whether the variability in contact hours in specific subject areas had diminished over the previous decades. Using the methodology of the 1994 Bourlioux/EAFP study, the 2011 PHARMINE study gathered data on the contact hours in specific subject areas in the EU member states with pharmacy faculties: the 11 of the 1994 study (see above) plus the 14 countries that had joined the EU at a later date (Austria, Bulgaria, Czech Republic, Estonia, Finland, Hungary, Latvia, Lithuania, Malta, Poland, Rumania, Slovakia, Slovenia, Sweden); the data were revised for this paper with the addition of those for Croatia that joined the EU in 2013.

This paper looks secondly at whether the changes in pharmacy education with a shift towards more clinical activities (an increase in the importance of MEDISCI) correspond to changes in policy (as finalized in the $2013 \mathrm{EU}$ directive).

\section{Methods}

Information from across the EU countries on the number of contact hours in specific subject areas was compared for the years of 1994 and 2011. Data was obtained from the original 1994 Bourlioux/EAFP study and the 2011 PHARMINE survey, which is described in previous publications. As the latter was based on the 1994 survey, the questions and categories were similar with the main difference being that the PHARMINE survey added a topic on generic subjects.

Data on contact hours in specific subject areas (expressed as a percentage of total hours) for the 1994 Bourlioux/EAFP study were obtained from previous publications [6]. In the 2011 PHARMINE survey [7] an electronic questionnaire was sent out to at least two faculties per country (excepting countries with only one faculty, e.g., Estonia). The departments surveyed in the two studies were not necessarily the same. 
Work Programme 1 of the PHARMINE survey centred on the organisation of the activities of pharmacists and professional bodies. It revealed the national background pharmaceutical situation in each member state. Work Programme 2 gathered data on departments, their status (public or private), and their organisation (link to a medical or science faculty...) and on staff and student numbers, entry requirements, courses, and fees. Work Programme 3 looked at data on teaching and learning methods (hours spent on lectures/tutorials/practicals/ independent project work; traineeship; electives). The results of these three work Programmes have been published [8]. Work Programmes 5 and 6 studied the impact of the Bologna declaration and of the EU directive on pharmacy education [9], respectively. Work Programme 6 examined quality assurance in pharmacy education in the EU [10]. (Work Programme 4 dealt with dissemination of the PHARMINE results).

Work Programme 7 looked at the contact hours in specific subject areas shown in the annex. The subject areas were similar in the two studies with the exception of the introduction of a specific chapter for generic subjects in the PHARMINE survey.

The results of Work Programme 7 are presented here with, firstly, separate descriptive analyses of the 1994 and the 2011 studies to determine if there were consistent differences across all countries in the number of hours dedicated to the topic areas. Secondly a comparison of the results of the two studies was carried out to see if there were any differences. Thirdly results from the 2011 PHARMINE study were analysed to see whether the subject area MEDISCI was predominant.

\section{Statistical Analysis}

As normality of distributions is unknown for the type of data presented here the Kolmogorov-Smirnov test for deviations of distribution from normality [11] was performed. This showed that only $7 \%-14 \%$ of the data showed significant deviations from normality of distribution (results not shown), thus it was assumed that parametric tests would be robust enough [12].

Results are expressed as means \pm standard deviations, and coefficients of variation $(\%)=$ $(($ mean/standard deviation $) \times 100)$. Comparisons were made using one-way ANOVA followed by the Tukey test for multiple comparisons [13], two-way ANOVA followed by the Holm-Š́dák test for multiple comparisons[14], or linear regression ANOVA. Statistical analysis was performed using $\operatorname{GraphPad}^{\circledR,}[15]$ programs.

Complete data for each country can be obtained on the PHARMINE website [16]. These profiles were written by the various members of the PHARMINE consortium (see acknowledgements). Data were checked by the author with that available on the department website, where possible.

\section{Results}

Contact hours in specific subject areas in the 1994 Bourlioux/EAFP and in the 2011 PHARMINE survey ( $\mathrm{n}=11$ countries):

In the 1994 study, subject contact hours were ranked as follows: CHEMSI >> BIOLSCI > MEDISCI > PHARMTECH >> PHYSMATH > LAWSOC (subject areas: Appendix Table A1).

The Tukey test for multiple comparisons showed significant differences $(p<0.05)$ amongst contact hours in subject areas as follows: CHEMSCI greater than the other five; MEDISCI greater than 
PHYSMATH, PHARMTECH and LAWSOC; and LAWSOC smaller than all others except PHARMTECH. Coefficients of variability were high ranging from 21 to $83 \%$ (Table 1).

In the 2011 study, subject contact hours were ranked as follows: MEDISCI > CHEMSI >> PHARMTECH $>$ BIOLSCI $>$ PHYSMATH $>$ LAWSOC.

The Tukey test for multiple comparisons showed significant differences $(p<0.05)$ amongst contact hours in subject areas as follows: CHEMSCI greater than the other six except MEDISCI; MEDISCI greater than the other six except CHELSCI; and LAWSOC smaller than all others except GENERIC (Table 1). Coefficients of variability were high ranging from 29 to $60 \%$.

Table 1. Contact hours in specific subject areas (expressed as a percentage of total hours) in the 1994 Bourlioux/EAFP and in the 2011 PHARMINE survey $(n=11)$. See annex for explanation of subject areas.

\begin{tabular}{ccccccc}
\hline & CHEMSCI & PHYSMATH & BIOLSCI & PHARMTECH & MEDISCI & LAWSOC \\
\hline $\begin{array}{c}\text { Mean } \pm \text { standard } \\
\text { deviation }\end{array}$ & $33 \pm 7$ & $8 \pm 3$ & $21 \pm 6$ & $13 \pm 5$ & $19 \pm 7$ & $6 \pm 5$ \\
$\begin{array}{c}\text { Coefficient of } \\
\text { variation (\%) }\end{array}$ & 21 & 38 & 29 & 38 & 37 & 83 \\
$\quad \begin{array}{c}2011 \\
\begin{array}{c}\text { Mean } \pm \text { standard } \\
\text { deviation }\end{array}\end{array}$ & $26 \pm 11$ & $7 \pm 2$ & $13 \pm 5$ & $14 \pm 5$ & $28 \pm 8$ & $5 \pm 3$ \\
$\begin{array}{c}\text { Coefficient of } \\
\text { variation (\%) }\end{array}$ & 42 & 29 & 38 & 36 & 29 & 60 \\
\hline
\end{tabular}

Contact hours in specific subjects in the 2011 PHARMINE survey ( $\mathrm{n}=26$ countries):

Minimum and maximum percentages for CHEMSCI were 14 and 44; for PHYSMATH 2 and 11; for BIOLSCI 2 and 24; for PHARMTECH 6 and 23; for MEDISCI 16 and 42; for LAWSOC 1 and 16; and for GENERIC 1 and 24 (Table 2).

Ranking for mean percentages in subject areas was MEDISCI $>$ CHEMSCI $>$ PHARMTECH $>$ BIOLSCI $>$ GENERIC $>$ PHYSMATH $>$ LAWSOC.

The Tukey test (columns = subject area) showed that there were significant differences in that CHEMSCI was greater than all others except MEDSCI; MEDSCI was greater than all others except CHEMSCI; and that PHARMTECH was greater than PHYSMATH, LAWSOC and GENERIC. Two-way ANOVA (columns = subject area, rows = countries) showed a significant effect of subject areas but not of countries.

There were large coefficients of variation ranging from $25 \%$ for MEDSIC to $74 \%$ for GENERIC. 
Table 2. Contact hours in specific subject areas (expressed as a percentage of total hours) in the 2011 PHARMINE survey $(\mathrm{n}=26)$.

\begin{tabular}{|c|c|c|c|c|c|c|c|}
\hline & CHEMSCI & PHYSMATH & BIOLSCI & PHARMTECH & MEDISCI & LAWSOC & GENERIC \\
\hline Austria & 44.0 & 2.0 & 22.0 & 14.0 & 16.0 & 0.6 & 1.0 \\
\hline Belgium & 24.0 & 9.0 & 11.0 & 18.0 & 27.0 & 2.0 & 8.0 \\
\hline Bulgaria & 31.0 & 7.0 & 11.0 & 13.0 & 24.0 & 7.0 & 7.0 \\
\hline Croatia & 24.9 & 4.2 & 9.2 & 8.9 & 26.9 & 2.5 & 23.3 \\
\hline $\begin{array}{l}\text { Czech } \\
\text { Republic }\end{array}$ & 17.0 & 5.0 & 8.0 & 22.0 & 19.0 & 13.0 & 16.0 \\
\hline Denmark & 42.0 & 7.0 & 7.0 & 16.0 & 16.0 & 9.0 & 3.0 \\
\hline Estonia & 21.0 & 4.0 & 2.0 & 21.0 & 39.0 & 10.0 & 3.0 \\
\hline Finland & 20.0 & 5.6 & 2.5 & 21.9 & 28.8 & 15.6 & 5.6 \\
\hline France & 17.6 & 9.5 & 17.9 & 5.9 & 42.0 & 2.2 & 5.0 \\
\hline Germany & 39.8 & 4.5 & 10.9 & 13.4 & 28.3 & 2.1 & 3.8 \\
\hline Greece & 39.3 & 5.8 & 14.2 & 8.2 & 15.9 & 2.7 & 14.0 \\
\hline Hungary & 27.2 & 5.2 & 5.2 & 16.0 & 28.5 & 3.9 & 14.2 \\
\hline Ireland & 13.6 & 11.1 & 7.1 & 18.3 & 35.5 & 7.3 & 7.1 \\
\hline Italy & 32.4 & 7.2 & 10.4 & 9.1 & 31.5 & 4.8 & 2.2 \\
\hline Latvia & 27.7 & 6.4 & 6.4 & 20.2 & 26.6 & 8.5 & 6.4 \\
\hline Lithuania & 21.3 & 2.0 & 8.9 & 8.9 & 27.7 & 7.4 & 23.8 \\
\hline Malta & 15.4 & 7.2 & 12.7 & 15.4 & 30.8 & 3.6 & 15.0 \\
\hline Netherlands & 20.1 & 3.9 & 10.6 & 14.2 & 31.1 & 8.3 & 11.8 \\
\hline Poland & 21.3 & 4.1 & 8.0 & 15.9 & 38.2 & 6.2 & 6.2 \\
\hline Portugal & 19.6 & 6.8 & 14.6 & 14.9 & 32.2 & 12.0 & 1.2 \\
\hline Rumania & 26.1 & 8.7 & 15.8 & 14.1 & 24.9 & 3.7 & 6.6 \\
\hline Slovakia & 28.8 & 8.8 & 10.9 & 14.4 & 27.6 & 3.4 & 6.0 \\
\hline Slovenia & 27.0 & 8.5 & 8.5 & 22.0 & 21.0 & 8.5 & 4.7 \\
\hline Spain & 23.5 & 5.5 & 19.9 & 11.0 & 27.6 & 5.5 & 7.0 \\
\hline Sweden & 18.3 & 11.3 & 12.8 & 19.5 & 21.5 & 11.8 & 5.0 \\
\hline $\begin{array}{l}\text { United } \\
\text { Kingdom }\end{array}$ & 13.6 & 5.7 & 23.9 & 22.7 & 23.9 & 3.4 & 6.8 \\
\hline Mean & 25.3 & 6.4 & 11.2 & 15.3 & 27.4 & 6.3 & 8.2 \\
\hline $\begin{array}{l}\text { Standard } \\
\text { deviation }\end{array}$ & 8.6 & 2.5 & 5.4 & 4.8 & 6.8 & 3.9 & 6.1 \\
\hline $\begin{array}{l}\text { Coefficient } \\
\text { of variation } \\
(\%)\end{array}$ & 33.9 & 38.4 & 48.5 & 31.2 & 25.0 & 61.8 & 74.3 \\
\hline
\end{tabular}

There was a significant inverse linear relationship between MEDSCI and CHEMSCI (CHEMSCI $=-0.61 \times$ MEDSCI $\left.+43, R^{2}=0.26, p<0.05\right)$; Figure 1 . 
Figure 1. Linear relationship between MEDISCI and CHEMSCI $(\mathrm{n}=26$ countries).

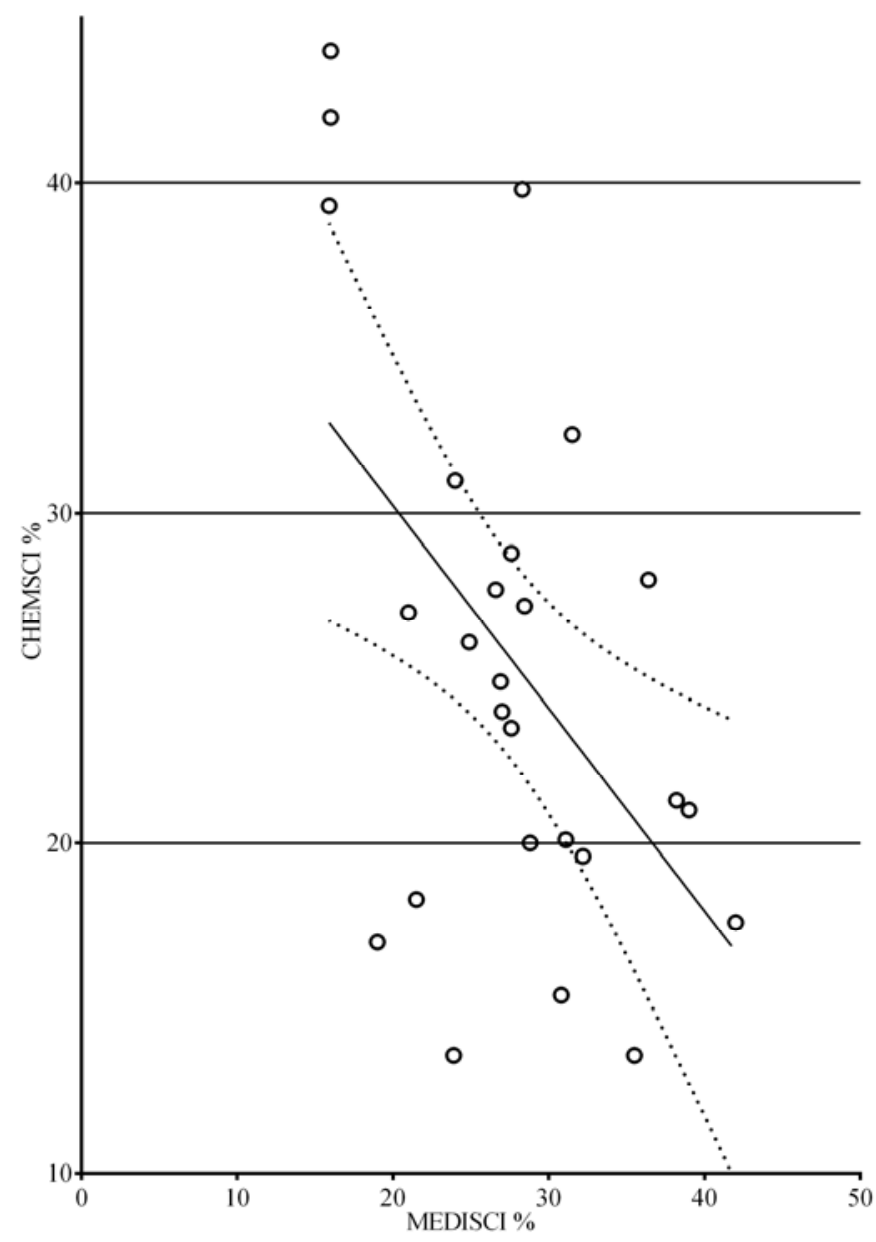

\section{Discussion}

\subsection{Methodology.}

In both surveys all the participants were members of the EAFP. Thus this study does not involve randomly drawn departments. In addition the departments surveyed in the second study were not necessarily the same as those surveyed in the first. The impact of this on results is unknown. In 1994 the European Economic Community was composed of a small number of member states most with a large population (> 10,000,000): Belgium, France, Germany, Greece, Italy, The Netherlands, Portugal, Spain, and the United Kingdom). In 2014 the EU has more than doubled in size as many countries with smaller populations have joined. In larger countries there are several pharmacy departments $(>20$ in France, Germany, Spain and the UK) and national bodies fix courses. In smaller countries there may be only one or two departments and these tend to look more towards EU organisations for guidance on courses. Thus the contexts of the 1994 Bourlioux survey and of the PHARMINE survey are different. Finally, Scotland represented the UK in the 1994 Bourlioux/EAFP survey, whereas as England represented the UK in the PHARMINE study. Organisation of pharmacy education in the two countries is not identical but similar. In most cases each member state was represented by data from a single department, in a few cases by two departments. There was no attempt to survey a number of departments relative to the size of the country. 
The organisation of the subject areas used in the 2011 PHARMINE study was that used by the 1994 Bourlioux/EAFP survey, the latter being based on the EEC 1985 directive (see Appendix Table A1). This allows comparison between the two studies and evaluation of possible evolution. However, other patterns of organisation are possible. In some faculties of pharmacy, "Pharmaceutical Sciences" contains the core subject areas in pharmaceutical education and research. This encompasses pharmaceutical technology, pharmacological sciences (including pharmacology-basic and clinicalpharmacokinetics, pharmacotherapy, toxicology, i.e., all drug action and use-related subjects such as medical devices, drugs in veterinary medicine, etc.) and social pharmacy. All the other subjects pertain strictly speaking to biomedical sciences and are grouped in what is called "Medicinal Sciences". In other words anatomy, physiology, etc. are in fact "Biomedical Sciences" (not "Biomedicinal") and the drug-related subjects (even though they are included in medicinal sciences) are within "Pharmacological Sciences". In particular, for example radiochemistry may be included in CHEMSCI and pharmaceutical care in LAWSOC.

Finally, there are also organisational differences between the EU directive 2013/55 and modern-day pharmacy education and practice. Thus, for example, clinical chemistry (or clinical biology) exists as an area of pharmacy practice and education in many member states but is not included in EU directive 2013/55.

\subsection{Evolution in Subject Areas between the 1994 and 2011 Surveys}

Percentages for PHYSMATH, BIOLSCI and PHARMTECH showed little change. CHEMSCI decreased from $33 \%$ to $26 \%$, that for BIOLSCI from $21 \%$ to $13 \%$, and that for MEDSCI increased from $19 \%$ to $28 \%$.

The coefficients of variation for means of hours in subject areas were similar in the two surveys. Thus the variability between member states has not decreased since the 1990s in spite of the staff and student exchange between countries via the Erasmus [17] and other programmes, and course harmonization tools such as the European Credit Transfer and Accumulation System (ECTS) [18].

It could be argued that the differences (variability) among the pharmacy curricula are not necessarily negative. Variability in educational procedures can be useful as it allows academic freedom to try other approaches, and prevents departments from all making the same mistake.

Finally it remains to be seen if variability in pharmacy curricula is really producing significant variability in pharmacists' competences for practice.

\subsection{A More "Clinical" Education and Practice in Pharmacy?}

There is a shift in pharmacy education over the previous decades from courses oriented towards CHEMSCI to those oriented towards MEDSCI. In the 1994 study MEDISCI was ranked third in number of contact hours, far behind CHEMSCI, whereas in the 2011 study MEDSCI was ranked first.

The above change in pharmacy education to more "clinical" courses is in line with the main changes in the directive between 1985 and 2013 and the inclusion of notions of:

(1) safe and efficacious medicinal products

(2) provision of information and advice on medicinal products...including on their appropriate use 
(3) reporting of adverse reactions of pharmaceutical products

(4) provision of personalised support for patients

(5) contribution to local or national public health campaigns

Thus the list of specific activities of a pharmacist given in the 1985/432/EEC directive has been extended by additions (in bold below) in the 2013/55/EU directive:

(a) preparation of the pharmaceutical form of medicinal products

(b) manufacture and testing of medicinal products

(c) testing of medicinal products in a laboratory for the testing of medicinal products

(d) storage, preservation and distribution of medicinal products at the wholesale stage

(e) supply, preparation, testing, storage, distribution and dispensing of safe and efficacious medicinal products of the required quality in pharmacies open to the public

(f) preparation, testing, storage and dispensing of safe and efficacious medicinal products of the required quality in hospitals

(g) provision of information and advice on medicinal products as such, including on their appropriate use

(h) reporting of adverse reactions of pharmaceutical products to the competent authorities

(i) personalised support for patients who administer their medication

(j) contribution to local or national public health campaigns

The above changes in the directive underlie a shift in the practice of pharmacy towards a more "clinical" role with involvement of more MEDISCI elements. This ties in with the trend towards courses with a higher MEDISCI percentage noted above.

Albeit, the linear relationship between CHEMSCI and MEDISCI (Figure 1) reveals that there are exceptions with some countries (e.g., Austria, Denmark, Germany) giving more "chemical" courses as judged from the relative hours dedicated to CHEMSCI and MEDISCI. This inverse relationship also shows that alongside countries like Poland, Estonia and France with a more "clinical" course, there are countries like Romania, Hungary and Slovenia with a "balanced" curriculum.

The change to a more "clinical" approach is not a uniquely EU phenomenon as judged by the increase world-wide in the number of publications on, for example, "pharmaceutical care" from 1 in 1990 to 104 in 2011, with 50 citations to articles on pharmaceutical care in 1995, and 1300 in 2011.

\section{Conclusions}

The conclusions to this study are:

- Since the 1990 s there has been no decrease in the variability in pharmacy courses amongst departments in different countries. This raises the question of the difference between the notion of "the broad comparability of training courses in the Member States" as outlined in the 1985 EEC directive, and the reality of the variability of EU pharmacy education systems.

- In the EU, there has been a shift towards more "clinical" courses with a greater MEDISCI content. This global shift from courses oriented towards chemical sciences to those oriented towards medicinal sciences coincides with the recognition - in the latest version of the EU directive_ of a more important "clinical" role for pharmacists. 


\section{Acknowledgments}

The author thanks the following persons who provided the raw data:

C. Noe. University of Vienna. Austria.

B. Rombaut. H. Halewijck and B. Thys. Vrije Universiteit Brussel. Faculty of Medicine and Pharmacy. Dept. Pharmaceutical Biotechnology and Molecular Biology. Brussels. Belgium.

V. Petkova and S. Nikolov. University of Sofia. Faculty of Pharmacy. Sofia. Bulgaria.

V. Belcheva. Sanofi-Aventis. Sofia. Bulgaria.

M. Z. Končić. University of Zagreb. Faculty of Pharmacy and Biochemistry. Zagreb Croatia.

D. Jonjic. Croatian Chamber of Pharmacists. Zagreb. Croatia.

Crnkovic. Hospital pharmacy. Psychiatry Clinic. Zagreb. Croatia.

M. Polasek. Faculty of Pharmacy. Charles University. Prague. Czech Republic.

U. Madsen and B. Fjalland. Faculty of Pharmaceutical Sciences. University of Copenhagen. Denmark.

M. Brandl. Faculty of Science. University of Southern Denmark. Denmark.

M. Ringkjøbing-Elema. EIPG / The Association of Danish Industrial Pharmacists. Copenhagen. Denmark.

P. Veski and D. Volmer. Department of Pharmacy. University of Tartu. Tartu. Estonia.

J. Hirvonen and A. Juppo. University of Helsinki. Faculty of Pharmacy. Finland.

Capdeville-Atkinson. Lorraine University. Nancy. France.

Marcincal. Faculté de Pharmacie. Université de Lille 2. Lille. France.

V. Lacamoire and I. Baron. Conseil National de l'Ordre des Pharmaciens. Paris. France.

R. Süss and R. Schubert. University of Freiburg. Freiburg. Germany.

P. Macheras. E. Mikros and D. M. Rekkas. School of Pharmacy. University of Athens. Athens. Greece.

K. Poulas. School of Pharmacy. University of Patras. Patras. Greece.

G. Soos and P. Doro. Faculty of Pharmacy. University of Szeged. Szeged. Hungary.

J. Strawbridge and P. Gallagher. Royal College of Surgeons in Ireland. Dublin. Ireland.

L. Horgan. Pharmaceutical Society of Ireland. PSI—The Pharmacy Regulator. Dublin. Ireland.

Rossi. and P. BLASI Faculty of Pharmacy. University of Perugia. Perugia. Italy.

R. Muceniece. Faculty of Medicine of University of Latvia. Riga. Latvia.

Maurina. Faculty of Pharmacy. Riga. Latvia.

Saprovska. Latvian Branch. European Industrial Pharmacists' Group (EIPG). Riga. Latvia.

V. Briedis and M. Sapragoniene. Lithuanian University of Health Sciences. Kaunus. Lithuania.

L. M. Azzopardi and A. S. Inglott. University of Malta. Department of Pharmacy. Msida. Malta.

T. Schalekamp. Utrecht University. Faculty of Science. Department of Pharmaceutical Sciences.

Utrecht. The Netherlands.

H. J. Haisma. University of Groningen. School of Life Sciences. Pharmacy and Pharmaceutical

Sciences. Groningen. The Netherlands.

S. Polak and R. Jachowicz. Faculty of Pharmacy with Division of Medicinal Analysis.

Jagiellonian University Medical College. Krakow. Poland.

J. A. G. Morais and A.M. Cavaco. Faculdade de Farmácia Universidade de Lisboa. Lisbon. Portugal.

Mircioiu and C. Rais. Faculty of Pharmacy. University of Medicine and Pharmacy "Carol

Davila”. Bucharest. Romania. 
J. Kyselovič and M. Remko. Faculty of Pharmacy. Comenius University. Odbojarov 10. Bratislava. 83232. Slovakia.

Bozic and S. Gobec. University of Ljubljana. Faculty of Pharmacy. Ljubljana. Slovenia.

B. DEL Castillo-Garcia. Facultad de Farmacia. Universidad Complutense de Madrid. Madrid. Spain.

L. Recalde and A. Sanchez Pozo. Facultad de Farmacia. Universidad de Granada. Granada. Spain.

R. Hansson and E. Björk. Faculty of Pharmacy. Uppsala University; G. TOBIN. Sahlgrenska Academy. Sweden.

K. A Wilson. Aston Pharmacy School. Aston. UK.

G. B. Lockwood. University of Manchester. School of Pharmacy. Manchester. UK.

The opinions expressed in this paper are those of its author.

\section{Conflicts of Interest}

The author declares no conflict of interest.

\section{References}

1. Council Directive of 16 September 1985 concerning the coordination of provisions laid down by law, regulation or administrative action in respect of certain activities in the field of pharmacy. Available online: http://eur-lex.europa.eu/legal-content/EN/TXT/PDF/ ?uri=CELEX:31985L0432\&from=EN (accessed on 23 July 2014).

2. European Association of Faculties of Pharmacy (EAFP). Available online: http://eafponline.eu/ (accessed on 3 August 2014).

3 ERASMUS Subject Evaluations: Summary Reports of the Evaluation Conferences by Subject Area, volume 1 pharmacy. Available online: http://ec.europa.eu/education/erasmus/doc/publ/ conf_en.pdf (accessed on 23 July 2014).

4 PHARMINE: pharmacy education in Europe. Available online: http://www.pharmine.org/ (accessed on 23 July 2014).

5 EU directive 2013/55/EU on the recognition of professional qualifications. Available online: http://eur-lex.europa.eu/LexUriServ/LexUriServ.do?uri=OJ:L:2005:255:0022:0142:EN:PDF (accessed on 23 July 2014).

6 Bourlioux, P. Proceedings of the 2nd European meetings of the faculties, schools and institutes of pharmacy, Berlin, September 1994. Available online: http://enzu.pharmine.org/media/filebook/ files/Bourlioux_full_report.pdf(accessed on 23 July 2014).

7 The PHARMINE WP7 survey. Available online: http://enzu.pharmine.org/media/filebook/ files/PHARMINE\%20WP7\%20survey\%20of\%20European\%20HEIs\%200309.pdf (accessed on 23 July 2014)

8 Atkinson, J; Rombaut, B. The 2011 PHARMINE report on pharmacy and pharmacy education in the European Union. Pharm. Pract. 2011, 9, 169-187.

9 Atkinson; J; Rombaut, B. The PHARMINE study on the impact of the European Union directive on sectoral professions and of the Bologna declaration on pharmacy education in Europe. Pharm. Pract. 2011, 9, 188-194. 
10 Guimarães Morais, J.A.; Cavaco, A.M.; Rombaut, B.; Rouse, M.; Atkinson, J. Quality assurance in European pharmacy education and training. Pharm. Pract. 2011, 9, 195-199.

11 Kolmogorov-Smirnov test for deviations of distribution from normality. Available online: http://www.graphpad.com/www/data-analysis-resource-center/blog/new-in-prism-6-kolmogorovsmirnov-test/ (accessed on 3 August 2014)

12 Raschi, D.; Guiard, V. The robustness of parametric statistical methods. Psychol. Sci. 2004, 4, 175-208.

13 Tukey test for multiple comparisons. Available online: http://www.graphpad.com/guides/prism/ 6/statistics/index.htm?stat_the_methods_of_tukey_and_dunne.htm (accessed on 3 August 2014).

14 Holm-Š́ídák test for multiple comparisons. Available online: http://www.graphpad.com/guides/ prism/6/statistics/index.htm?stat_holms_multiple_comparison_test.htm (accessed on 3 August 2014).

$15 \mathrm{GraphPad}^{\circledR}$. Available online: http://www.graphpad.com/ (accessed on 23 July 2014).

16 Country profiles on the PHARMINE website. Available online: http://www.pharmine.org/ losse_paginas/Country_Profiles/ (accessed on 23 July 2014).

17 Erasmus. Available online: https://www.erasmusplus.org.uk/ (accessed on 3 August 2014).

18 European Credit Transfer and Accumulation System (ECTS). Available online: http://ec.europa.eu/education/tools/docs/ects-guide_en.pdf (accessed on 23 July 2014).

\section{Appendix}

Table A1. Subject areas in the 1985 EEC directive together with additions in 1994

Bourlioux/EAFP survey (non-italic) and in the 2011 PHARMINE survey (italic).

\begin{tabular}{|c|c|}
\hline $\begin{array}{l}\text { Subject Areas in Directive } \\
85 / 432 / \text { EEC }\end{array}$ & Additional Subjects \\
\hline \multicolumn{2}{|l|}{$\begin{array}{l}\text { 1. Chemistry } \\
\text { (CHEMSCI) }\end{array}$} \\
\hline General and inorganic chemistry & Medical physico-chemistry \\
\hline Organic chemistry & Pharmacopeia analysis \\
\hline \multirow{2}{*}{\multicolumn{2}{|c|}{$\begin{array}{l}\text { Analytical chemistry } \\
\text { Pharmaceutical chemistry including } \\
\text { analysis } \\
\text { of medicinal products }\end{array}$}} \\
\hline & \\
\hline & Structure-activity relationships / drug design \\
\hline \multicolumn{2}{|l|}{$\begin{array}{l}\text { 2. Physics / Mathematics / } \\
\text { Computing / Statistics } \\
\text { (PHYSMATH) }\end{array}$} \\
\hline Physics & $\begin{array}{l}\text { Mathematics / Computing / Statistics } \\
\text { Pharmaceutical calculations } \\
\text { Information technology, information technology applied to } \\
\text { community pharmacy, information technology applied to } \\
\text { national healthcare } \\
\text { Experimental design and analysis }\end{array}$ \\
\hline
\end{tabular}


Table A1. Cont.

\begin{tabular}{|c|c|}
\hline $\begin{array}{l}\text { Subject Areas in Directive } \\
85 / 432 / \text { EEC }\end{array}$ & Additional Subjects \\
\hline \multicolumn{2}{|l|}{$\begin{array}{l}\text { 3. Biology / Biochemistry / } \\
\text { Pharmacognosy } \\
\text { (BIOLSCI) }\end{array}$} \\
\hline \multirow[t]{2}{*}{$\begin{array}{l}\text { General and applied biochemistry } \\
\text { (medical) } \\
\text { Plant and animal biology } \\
\text { Microbiology/Pharmacognosy }\end{array}$} & Phyto-chemistry \\
\hline & $\begin{array}{l}\text { Mycology } \\
\text { Molecular biology } \\
\text { Genetics }\end{array}$ \\
\hline \multicolumn{2}{|l|}{$\begin{array}{l}\text { 4. Pharmaceutics / Technology } \\
\text { (PHARMTECH) }\end{array}$} \\
\hline \multirow[t]{10}{*}{ Pharmaceutical technology } & Finished medicinal products \\
\hline & Drug disposition and metabolism / pharmacokinetics \\
\hline & Novel drug delivery systems \\
\hline & Pharmaceutical research and development \\
\hline & Drug production \\
\hline & Quality assurance in production \\
\hline & $\begin{array}{l}\text { Drug / new chemical entity registration and regularization } \\
\text { Common technical document: pharmaceutical quality, safety } \\
\text { pharmacology and toxicology efficacy (preclinical and } \\
\text { clinical studies) } \\
\text { Ophthalmic preparations }\end{array}$ \\
\hline & Medical gases \\
\hline & Cosmetics \\
\hline & $\begin{array}{l}\text { Management strategy in industry } \\
\text { Economics of the pharmaceutical industry and of research } \\
\text { and development }\end{array}$ \\
\hline
\end{tabular}

5. Medicine / Pharmacology /

Toxicology

(MEDISCI)

Anatomy, physiology, medical terminology

Pathology / Histology / Nutrition

Pharmacology / pharmacotherapy

Haematology / Immunology

Toxicology

Parasitology / Hygiene

Emergency therapy 
Table A1. Cont.

\begin{tabular}{ll}
\hline Subject Areas in Directive & Additional Subjects \\
\hline Pharmacology / pharmacotherapy & Non-pharmacological treatment \\
Toxicology & Clinical chemistry / bio-analysis (of body fluids) \\
Radiochemistry & Dispensing process, drug prescription, prescription analysis \\
(detection of adverse effects and drug interactions) \\
\hline Generic drugs \\
Planning, running and interpretation of the data of clinical \\
trials \\
Medical devices \\
Orthopaedics \\
OTC medicines, complementary therapy \\
At-home support and care \\
Skin illness and treatment \\
Homeopathy \\
Phyto-therapy \\
Drugs in veterinary medicine \\
Pharmaceutical care, pharmaceutical therapy of illness and \\
disease
\end{tabular}

6. Law / Social Aspects of Pharmacy

(LAWSOC)

\begin{tabular}{ll}
\hline Legislation / professional ethics & Philosophy / Economics \\
\cline { 2 - 2 } Management / History of pharmacy \\
\cline { 2 - 2 } Public health \\
\hline Social sciences \\
Forensic science \\
Public health / health promotion \\
Quality management \\
Epidemiology of drug use (pharmaco-epidemiology) \\
Economics of drug use (pharmaco-economics) \\
\hline
\end{tabular}

7.Generic Competences (GENERIC)

\begin{tabular}{l} 
General knowledge \\
\hline Academic literacy \\
Languages \\
First aid \\
Communication \\
Management \\
Practical skills
\end{tabular}

(C) 2014 by the authors; licensee MDPI, Basel, Switzerland. This article is an open access article distributed under the terms and conditions of the Creative Commons Attribution license (http://creativecommons.org/licenses/by/3.0/). 